\title{
Medical management of chronic pain
}

\author{
Philip Peng, MBBS, FRCPC, Founder (Pain Medicine)
}

Department of Anesthesia, University Health Network, University of Toronto, Toronto, ON, Canada

Cite as: Can Urol Assoc J 2018;12(6Suppl3):S155-6. http://dx.doi.org/10.5489/cuaj.5323

\section{Introduction}

A clinician usually refers to medical management as the treatment modality employing pharmacologic agents. For urologists choosing a pharmacologic agent(s) for their patients, the following tips can be useful.

\section{Practice tips}

\section{Tip 1: Consider a multidisciplinary and multimodal approach}

Pain impacts the psychological well-being, which in turn, modulates the perception of pain. In patients with depression, anxiety disorder, post-traumatic stress, hypervigilance to pain, or high pain catastrophizing scale, medical management alone is unlikely to be effective unless the psychological issues are addressed and managed. The effect size of most pharmacologic agents is usually modest. Further escalating the dose to optimize the effect size is limited by the dose-related adverse effects. Thus, it is prudent to weigh the beneficial effects of pharmacologic agents against other modalities (Fig. 1).

\section{Tip 2: Go back to the basics of pain classification}

After a thorough assessment, one should determine the type of pain: neuropathic or nociceptive (somatic or visceral). Medical treatment differs depending on the type of pain. For instance, neuropathic pain medication is used when the clinical picture is neuropathic-dominant. Tricyclic antidepressant (TCAs) and serotonin and norepinephrine reuptake inhibitors (SNRIs) can be considered in patients with myofascial or neuropathic pain, whereas acetaminophen and non-steroidal anti-inflammatory drugs (NSAIDs) are not effective for neuropathic pain.

\section{Tip 3: Become familiar with the neuropathic pain algorithm}

There are various classes of pharmacologic agents adopted in different guidelines. One should be familiar with the three groups of agents with strongly graded recommendations (Table 1). If those fail, it is reasonable to refer patients to a pain specialist.

In general, when you start first-line neuropathic medication, consider a "start low and go slow" plan. Typically, gabapentin and pregabalin are started at low doses are then increased every 3-5 days to the target dose. The dose of TCAs for neuropathic pain is, in general, much lower than the dose for depression. The most common side effect of duloxetine is nausea and is usually minimized by starting at $30 \mathrm{mg}$ once daily for one week, followed by $60 \mathrm{mg}$ once daily. We usually advise the patient to take duloxetine after dinner. Another SNRI is venlafaxine, but the optimal dose for neuropathic pain is usually at a higher dose (>225 mg/day).

\section{Tip 4: Drugs that can be considered for somatic pain}

Acetaminophen is commonly used because of the safety profile. The maximum daily dose in Canada is $4 \mathrm{~g}$. In elderly patient, the maximum daily dose should be cut to half (2 g/ day). NSAIDs are useful for the short-term, but one should be cautious about the long-term side effects (gastrointestinal, renal, bleeding, and cardiac).

Both TCAs and SNRIs can be useful for myofascial components.

Another class is the cannabinoid group, including nabilone. Nabilone is a synthetic drug of tetrahydrocannbinol (THC) and the therapeutic effects are intrinsic analgesia and pain experience modulation (makes the pain less unpleasant). The usual starting dose is $0.5-1 \mathrm{mg}$ per day, and it can be titrated up to $2 \mathrm{mg}$ three times daily.

\section{Tip 5: Be cautious if you want to start opioids}

The current understanding of opioid pharmacology and the recent opioid epidemic caution us on the use of opioids. While an opioid is a useful drug to alleviate pain, the evidence to support the use of high doses for long periods is very weak. In fact, the concept of opioid-induced hyper- 


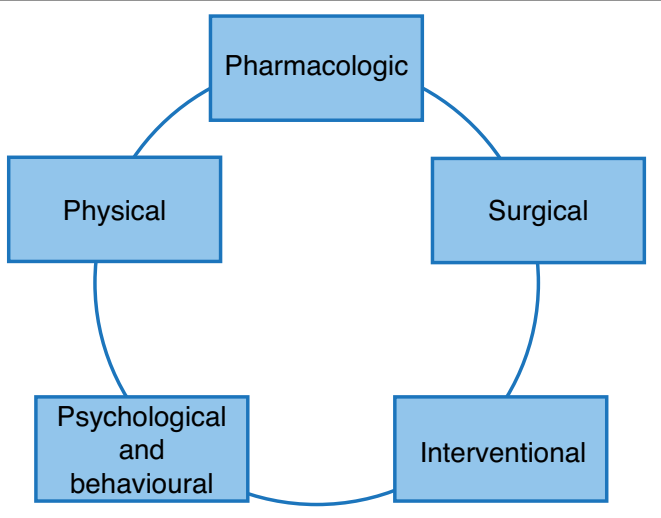

Fig. 1. Multimodal approach to management of chronic pain.

algesia suggests that high-dose opioids for long-term use can actually decrease the pain threshold and increase pain sensitivity. Interestingly, one of the methods of inducing pain in animal pain models is to expose the animals to chronic opioids. The most recent Canadian opioid guideline is very similar to the U.S. Food and Drug Administration recommendation and suggests a total daily dose of $<50 \mathrm{mg} /$ day morphine equivalent.

\section{Tip 6: Other modes of delivery of pharmacologic agents}

Other modalities can be useful for medical management of pain. One is topical. As a matter of fact, the vehicle (cream base) dictates the absorption and the topical application can be used for transdermal delivery. Common cream bases are Lipoderm $^{\circledR}$ or pluronic lecithin organogel (PLO); these can be used to enhance systemic absorption. A few commonly used topical agents are listed in Table 2 . In addition, capsaicin $8 \%$ is commercially available for neuropathic pain.

\begin{tabular}{|c|c|c|}
\hline Class & Usual doses & Common side effects \\
\hline Gabapentinoids & & Dizziness, downiness, dry \\
\hline Gabapentin & $\begin{array}{l}\text { 300-2400 mg/day } \\
\text { in 3-4 divided }\end{array}$ & $\begin{array}{l}\text { month and constipation, } \\
\text { blurring vision, bloating }\end{array}$ \\
\hline Pregabalin & $\begin{array}{l}\text { doses } \\
50-450 \mathrm{mg} \text { in } 2-3 \\
\text { divided doses }\end{array}$ & $\begin{array}{c}\text { cognitive impairment, } \\
\text { increase appetite }\end{array}$ \\
\hline $\begin{array}{l}\text { Tricyclic } \\
\text { antidepressant }\end{array}$ & & $\begin{array}{l}\text { Dizziness, drowsiness, dry } \\
\text { mouth and constipation; }\end{array}$ \\
\hline Amitryptline & $10-100 \mathrm{mg}$ OD & caution: cardiac patient \\
\hline Nortryptyline & $10-100 \mathrm{mg}$ OD & (effects on heart rate, \\
\hline Desipramine & $10-100 \mathrm{mg}$ OD & $\begin{array}{c}\text { blood pressure); elderly } \\
\text { (balance, glaucoma and } \\
\text { urine retention); young } \\
\text { female (weight gain) }\end{array}$ \\
\hline $\begin{array}{l}\text { SNRI } \\
\text { Duloxetine }\end{array}$ & 30-90 mg OD & $\begin{array}{l}\text { Nausea, dizziness, } \\
\text { drowsiness, agitation, } \\
\text { constipation, diarrhea }\end{array}$ \\
\hline
\end{tabular}

Table 2. Topical agents for chronic pain

\begin{tabular}{|c|c|c|}
\hline $\begin{array}{l}\text { Commonly used } \\
\text { topical }\end{array}$ & Base & Indication \\
\hline Diclofenac 6-8\% & DiffusiMax & Soft tissue pain \\
\hline $\begin{array}{l}\text { Lidocaine } 5-10 \% \\
\text { Gabapentin } 6 \% \\
\text { Amitriptyline } 2 \% \\
\text { Ketamine 5-10\% }\end{array}$ & PLO or Lipoderm ${ }^{\circledast}$ & Neuropathic pain \\
\hline Baclofen 5\% & PLO or Lipoderm ${ }^{\circledR}$ & $\begin{array}{l}\text { Muscle relaxant fo } \\
\text { myofascial pain }\end{array}$ \\
\hline
\end{tabular}

Diazepam suppository is quite commonly used by pain specialists for pelvic myofascial pain and is usually prescribed at a dose of $5 \mathrm{mg} /$ day.

In patients with severe neuropathic pain, intravenous lidocaine infusion (3-5 mg/kg over 1-2 hours) can be offered to minimize the symptoms from abnormal pain sensitivity.

Competing interests: Dr. Peng reports no competing personal or financial conflicts related to this work.

This paper has been peer reviewed.

\section{Recommended reading}

1. Essential of Pain Medicine. Editors: Benzon H, Raja SN, Liu SS, Fishman SM, Cohen SP; Hurley RW, Malik K, Peng P. Elsevier.

2. Chronic Pain Management: A Practical Guide. Editors: Lynch M, Craig K, Peng P. Wiley

3. Basic Science of Pain: An Illustrated and Clinical Orientated Guide. Editors: Peng P, DeLeon 0. Philip Peng Educational Series.

4. Busse JW, Craigie $S$, Juurlink DN, et al. Guideline for opioid therapy and chronic non-cancer pain. CMAJ 2017;189:E659-E66. https://doi.org/10.1503/cmaj.170363

Correspondence: Dr. Philip Peng, Department of Anesthesia, University Health Network, University of Toronto, Toronto, ON, Canada; philip.peng@uhn.ca 